Panel Discussion

TITLE

The Golden Gate: Building Bridges between Research and Operations.

\begin{abstract}
Previous research has discussed the ongoing dilemma of implementing research-based findings in an applied setting. This panel will discuss lessons learned from various examples where bridges have been forged between research and operations, and examine ways to promote and achieve similar collaborations in other areas in the future.

\section{PRESS PARAGRAPH}

Implementing the findings of research studies and evidence-based recommendations within the world of industry is an issue in many field of science. However, it is essential that the recommendations and evidence from research is implemented and has impact in the 'real world,' or else the effectiveness of such research endeavors should be questioned. Based on recent experiences bridging research and operations, this panel will discuss how collaborations may be created, promoted, and maintained. Topics include creating opportunities for increased communication, incorporating the operational community in the definition of specific research questions, and identifying the final research 'deliverables/products' that are desired.
\end{abstract}


The Golden Gate: Building Bridges between Research and Operations.

Imagine the following scenario: while managers and others within an organization with decision making authority are seeking ways to improve their bottom line, academicians are busy developing and testing theories that will improve how organizations are run. The irony is that often these two worlds do not meet; more often than not, well validated theories and knowledge that is supported by evidence-based research does not reach those within organizations who can instigate change. Indeed, research suggests that managers look to best-selling literature for guidance and insight when dealing with organizational dilemmas rather than scientific journals (Offerman \& Spiros, 2001).

For the research and operational world to work together and avoid the above scenario, an ongoing effort must be made in which individuals from both research and operations communicate and are motivated to work with each other and make a conscientious effort to keep each other informed. However, most managers and researchers do not receive any direct training or mentoring on how to build strong collaborations between operations and research. Many I-O psychologists have real-world experiences with doing just this sort of bridging and the lessons learned from their endeavors could be used to progress the application of research in operational settings. The objective of the proposed panel discussion is to articulate what helps to make successful close collaborations between research and operations and to provide spell out acronym (SIOP) members with more practical knowledge and strategies for building these bridges to serve our field of practice well.

Brief Background

On March 9, 2009 the President of the United States issued a Whitehouse Memorandum for the heads of executive departments and agencies calling for the better use of science to 
"inform and guide decisions of my Administration on a wide range of issues" (Whitehouse, Office of the Press Secretary, 2009). Within the memorandum, the president noted several barriers that prevent science from being successfully applied to administrative decisions, including: the integrity and operational applicability of research findings, administrative support of open and honest research reports, objective fiscal support of operationally relevant research, and procedures and rules within organizations to facilitate mutually beneficial collaborations between operations and research. This memorandum applies to all sciences, and while it targets federal agencies, the sentiments included in it articulate many of the same issues apparent in applying research to meet operational objectives in any industry.

In the year following the President's memorandum, the American Psychological Association also issued a report on why psychology as a science is not consistently considered as a core Science, Technology, Engineering, and Mathematics (STEM) discipline (APA 2010) despite psychology's consistent contributions to public health, safety, education, and technological development. One of the four core recommendations to psychological practitioners and scientists in this report was to increase collaborations and involvements with other STEM disciplines and applications, and another of the four recommendations was to make our science more applicable to everyday life. The President's memorandum and APA's report remind us that the worth of a science field is often determined by the depth and breadth of its applications.

A perusal of SIOP conference programs over the last five years reveals that several conference presentations and posters show a deep and wide-spread application of our science to many practical and cutting-edge everyday issues such as (but not limited to) employee selection, retention, development, training, occupational health, and organizational resilience. A great 
many of these applications were made possible by successful collaboration with other sciences

and operations. Based on the abundance and variety of collaborations occurring within our field, one could argue that I-O psychologists have valuable experience with integrating research and operations in ways that provide useable products or improved services to organizations, inform public policy, and/ or progress scientific theory and knowledge through application. However, past presentations and publications within I-O psychology have not systematically discussed how I-O psychologists may best build and maintain these collaborations for the benefit of helping our own field become a more recognizable STEM discipline; and for the sake of helping public science, in general, learn how to build good collaborations that can overcome the barriers articulated in President Obama's memorandum.

\section{Proposed Session}

The target audience for the session is any SIOP member or student affiliate interested in doing research in an applied setting, applying research within an operational setting, or effectively informing public and organizational policies regarding research. At the conclusion of this session, attendees should have new ideas regarding ways to increase collaboration between research and operations within their own projects and organizations. The panel is comprised of individuals with recent experience forming extensive collaborations between research and operations. Efforts were made to bring together a diverse group representing different operational contexts, collaboration purposes, roles, methods, funding sources, and products. Below are brief biographical descriptions of the panelists.

Dr. David P. Baker joined IMPAQ International as a Principal Research Scientist and Vice President in March 2010. Before joining IMPAQ, he held positions as Director of the Health Services Research Institute within Quality Integration and Improvement at the Carilion Clinic, as an Associate Professor on the founding faculty for the Virginia Tech Carilion School of Medicine (VTCSOM) and with the American Institutes for Research (AIR). At AIR, he served as Project Director for all of AIR's TeamSTEPPS ${ }^{\circledR}$ projects. These include: the Program 
Evaluation of Medical Team Training in the Department of Defense; Development and Testing of a Rapid Response Team Training module within the TeamSTEPPS Curriculum; Support of the DoD Health Care Team Coordination Program to Evaluate TeamSTEPPS; and the TeamSTEPPS Collaborative. Overall the purpose of these efforts has been to transition the most current research findings on team performance into evidence-based tools that promote better teamwork in military treatment facilities and health care in general. Dr. Baker and his team received the 2007 M. Scott Myers Award for Applied Research in the Workplace for TeamSTEPPS.

Dr. Dana Broach is a personnel research psychologist at the Federal Aviation Administration's Civil Aerospace Medical Institute (CAMI). Dr. Broach has focused his own work and building collaborative research projects for CAMI on the relationship of knowledge, skills, abilities, and other personal characteristics to job and task performance in safety-critical aviation occupations. He directed collaborative research resulting in a response-option scored, empirically-keyed biographical data instrument for air traffic controllers. Currently, his work concentrates on identifying aptitudes needed for new controllers with the Next Generation Air Transportation System ("NextGen"), the FAA's umbrella "system of systems" for modernization of the National Airspace System. Dr. Broach has written more than 100 journal articles, book chapters, technical publications and conference presentations. He is a member of the Society for Industrial and Organizational Psychology, Association for Psychological Science, the Aerospace Medical Association, the Association for Aviation Psychology, the European Association for Aviation Psychology, the American Institute for Aeronautics and Astronautics, and the International Association for Applied Psychology.

LCDR Henry L. Phillips IV holds a Ph.D. in Industrial/Organizational Psychology with a minor in Statistics and is a commissioned officer in the United States Navy. Dr. Phillips is a winged Naval Aerospace Experimental Psychologist and he currently serves as the Operational Psychology Department Head at the Naval Aerospace Medical Institute in Pensacola FL. He previously served on the staff of the Chief of Naval Air Training as a policy advisor. Over the last decade, Dr. Phillips has been responsible for using research literature and collaborations with external researchers to influence Navy policies regarding selection and training. In particular, he has been an advocate for using internal and external research to shape the structure and content of the aviation personnel selection battery. Dr. Phillips is currently Assistant Specialty Leader of the Aerospace Experimental Psychology community, and Vice President of the U.S. Naval Aerospace Experimental Psychology Society (USNAEPS).

Dr. Lacey L. Schmidt is the Senior Scientist in Astronaut Selection and Training for the Behavioral Health and Performance (BHP) Operations Group at NASA Johnson Space Center. In her current role, Dr. Schmidt has been responsible for applying research from multiple fields to develop and implement a new Space Flight Resource Management training program for space station operations and an updated psychological selection and screening program for astronauts. Additionally, she has been responsible for interacting with BHP research to help solicit and monitor research in team training and selection that serves future NASA operations. Previously, Dr. Schmidt helped the University of Texas, School of Public Health to complete and apply research on how to reorganize work to reduce attrition for nurses at St. Luke's Episcopal Hospital. Before joining NASA's BHP group, she also acted as an organizational development 
manager for Aramark Health and was responsible for soliciting and implementing research integrating social exchange theory and OD practices in support of patient services. Dr. Schmidt is a member of the Society for Industrial and Organizational Psychology, the American Psychological Association, the Aerospace Medical Association, the Society of Human Resource Management, and the OD Network.

Session Chair:

Dr. Kimberly Smith-Jentsch is currently an associate professor in the department of psychology at the University of Central Florida (UCF). Her research focuses on training, mentoring, teams, interpersonal skills, and the use of simulation to assess performance. Throughout her career, Dr. Smith-Jentsch has been awarded over \$6M in contracts and grants to study these topics. She also has earned a number of awards for her work, including the M. Scott Myers Award for Applied Research in the Workplace (2001), the Dr. Arthur E. Bisson Award for Naval Technology Achievement (2000), and the NAVAIR Senior Scientist Award (2000). Dr. Smith-Jentsch's research has been published in the Journal of Applied Psychology, Personnel Psychology, Journal of Organizational Behavior, Journal of Vocational Behavior, and Human Factors. Together, her articles and book chapters have been cited over 600 times to date. She is currently a member of the editorial boards for the Journal of Applied Psychology and the Journal of Business and Psychology.

The session will focus on a series of questions posed by the chair and responses provided by the panelists. Questions to be posed include:

- What are some of the best opportunities to establish or develop collaborations between operations and research?

- As researchers, how can we better incorporate the operational community in the definition of specific research questions or otherwise produce more immediately applicable research for operations?

- As practitioners, how can we better inform the research community of our needs and the operational context to facilitate the development of more applicable research evidence and products?

- What are the most common barriers to successful collaborations between operations and research, and how can these be avoided or overcome? (i.e., What hasn't worked in your experience and how could that have been changed for the better?) 
- In your experience, what are the primary components of successful collaborations between operations and research? (i.e., What has worked well that we could repeat in future collaborations?)

An 80-minute time slot is requested for this session. The chair will begin by providing a 5minute introduction before facilitating a question and answer session for the next 65 minutes based on pre-planned questions (an average of 10 minutes discussion per question). After each panelist has provided input on a topic for the given question, audience members will be encouraged to ask questions related to the given question topic. The chair will be mindful of time limitations and move to the next question as necessary. Ten minutes will be left at the end of the session to ensure that the audience has the opportunity to ask questions that the panelists or chair had not considered. 


\section{References}

APA (2010). Report of the American Psychological Association 2009 Presidential Task Force On the Future of Psychology as a STEM Discipline. http://www.apa.org/science/about/psa/2010/08/stem-report.pdf.

Offerman, L. R., \& Spiros, R. K. (2001). The science and practice of team development: Improving the link. Academy of Management Journal, 44, 376-392.

The Whitehouse, Office of the Press Secretary (2009). MEMORANDUM FOR THE HEADS OF EXECUTIVE DEPARTMENTS AND AGENCIES, SUBJECT: Scientific Integrity http://www.whitehouse.gov/the_press_office/Memorandum-for-the-Heads-of-ExecutiveDepartments-and-Agencies-3-9-09/ 


\section{Participant Information}

\section{Session Chair:}

Kimberly Smith-Jentsch

Department of Psychology

Univ. of Central Florida

4000 Central Florida Blvd.

Orlando, FL 32816-1390

Phone: 1.407.823.3577

Email: kjentsch@mail.ucf.edu

Membership Status: Member

\section{Panelists:}

\begin{tabular}{|c|c|}
\hline $\begin{array}{l}\text { David P. Baker } \\
\text { IMPAQ International, LLC } \\
\text { 10420 Little Patuxent Parkway, Suite } 300 \\
\text { Columbia, MD } 21044 \\
\text { Phone: } \\
\text { Direct: } 1.443 .367 .0088 \text { ext. } 2259 \\
\text { Fax: } \quad 1.443 .367 .0477 \\
\text { Email: dbaker@impaqint.com }\end{array}$ & $\begin{array}{l}\text { Dana Broach } \\
\text { FAA Civil Aerospace Medical Institute } \\
\text { P.O. Box } 25082 \\
\text { Oklahoma City, OK } 73125 \\
\text { Voice: } 1.405 .954 .4839 \\
\text { Fax: 1.405.954.4852 } \\
\text { E-mail: dana.broach@ faa.gov }\end{array}$ \\
\hline Membership Status: Fellow & Membership Status: Member \\
\hline $\begin{array}{l}\text { LDCR Henry L. Phillips IV } \\
\text { Chief of Naval Air Training (CNATRA) } \\
\text { 250 Lexington Blvd, Ste } 102 \\
\text { Corpus Christi, TX } 78419 \\
\text { Phone: 1.361.438.7853 } \\
\text { Email: henry.phillips@ @ navy.mil }\end{array}$ & $\begin{array}{l}\text { Lacey L. Schmidt } \\
\text { Behavioral Health and Performance } \\
1290 \text { Hercules, Suite } 210 \\
\text { Houston, TX } 77058 \\
\text { Phone: } 1.281 .212 .1393 \\
\text { Fax: } \quad 1.281 .212 .1370 \\
\text { Email: Lschmidt@ wylehou.com }\end{array}$ \\
\hline Membership Status: Member & Membership Status: Member \\
\hline
\end{tabular}

